\title{
Visible Light Water Splitting Via Oxidized TiN Thin Films
}

Wilson Smith ${ }^{\mathrm{a} *}$, Houssam Fakhouri ${ }^{\mathrm{a}}$, Jerome Pulpytel ${ }^{\mathrm{a}}$, Shinsuke Mori ${ }^{\mathrm{b}}$, Rossana Grilli ${ }^{\mathrm{c}}$, Mark A. Baker ${ }^{\mathrm{c}}$, and Farzaneh Arefi-Khonsari ${ }^{\mathrm{a}}$

${ }^{a}$ Laboratoire de Génie des Procédés Plasma et Traitement de Surface Université Pierre et Marie Curie (UPMC), Chimie Paristech (ENSCP)

11 Rue Pierre et Marie Curie, 75231 Paris-France

${ }^{\mathrm{b}}$ Department of Chemical Engineering

Tokyo Institute of Technology

O-okayama Campus, South 1-, Tokyo, Japan

${ }^{\mathrm{c}}$ The Surface Analysis Laboratory

Faculty of Engineering and Physical Sciences

University of Surrey

Guildford,

GU2 7XH

UK

*corresponding author

Email: wilsonasmith@gmail.com

Phone: +33 (0)78 6048154 


\section{Abstract}

Thin films of TiN were prepared via RF magnetron reactive sputtering at various deposition pressures. The characteristics of the plasmas were measured by optical emission spectroscopy to optimize the conditions for the deposition of TiN coatings. After deposition, the thin films were annealed in a closed furnace at several different temperatures, and revealed the formation of different phases of $\mathrm{TiO}_{2}$. The resulting $\mathrm{TiN} / \mathrm{TiO}_{2}$ thin films showed drastic changes in their crystal structure, optical properties, and photoelectrochemical performance. By examining how the deposition pressure and post-deposition annealing conditions affected the TiN film structure and performance, samples were prepared to optimize visible light absorption and activity. A model for the oxidation process was proposed which described the structural change from $\mathrm{TiN}$ to $\mathrm{TiO}_{2}$ through optical, morphological, and crystalline characterization. This study has systematically shown the ability to tailor the optical, crystalline, and photoactive properties of $\mathrm{TiO}_{2}$ by tailoring the intrinsic properties of TiN thin films and subsequent annealing. These results can be utilized for many solar driven optoelectronic devices.

Keywords: Titanium Nitride, Nitrogen Doped Titanium Oxide, Phase Transformation, Photoelectrochemistry, Visible Light Water Splitting

Submitted to: Journal of Physical Chemistry C 


\section{INTRODUCTION}

$\mathrm{TiO}_{2}$ has been used as an effective photocatalyst and smart material for several decades, however, its major drawback is its inability to absorb and operate under visible light irradiation and its relatively low electron-hole pair lifetime. ${ }^{1-4}$ The most attractive methods for improving these deficiencies have been through doping and multi-layered nanostructure fabrication. Non-metals such as $\mathrm{C}, \mathrm{S}$, and $\mathrm{N}$ can be doped into $\mathrm{TiO}_{2}$, and have shown the ability to improve visible light photoactivity and functionality. ${ }^{5-7}$ In particular, nitrogen doping has received significant attention due to its small ionic radius and optimal electronic band positions. The photocatalytic efficiency of $\mathrm{TiO}_{2}$ can also be enhanced when it is in contact with a material that has a different Fermi energy level than itself, because it is possible to create effective charge separation which can extend the lifetime of photo-generated electron hole-pairs. $^{8-10}$ When the lifetime of electron-hole pairs is extended, it is possible to increase the catalytic reaction time, thus improving the functionality of the photocatalyst.

Extending the absorption range of $\mathrm{TiO}_{2}$ by nitrogen doping was first developed by Sato in $1986 .{ }^{11}$ Since then the fabrication methods to produce $\mathrm{N}^{-\mathrm{TiO}_{2}}$ have expanded greatly and now include sol-gel, ${ }^{12}$ hydrolysis, ${ }^{13}$ and nitriding $\mathrm{TiO}_{2}$ films, ${ }^{14}$ among many others. While there has been an abundance in the methods to create $\mathrm{N}$-doped $\mathrm{TiO}_{2}$, each process can form drastically different structures. For example, nitrogen can be incorporated in to the crystal lattice either substitutionally or interstitially. The nature and concentration of the doping can play a large role in the overall effectiveness of $\mathrm{TiO}_{2}$ to absorb visible light, through the reduction of the optical band gap, the introduction of stable energy levels within the band gap, or the prevalence of oxygen vacancies. ${ }^{7,11-13,15}$ A diagram with the band gap of pure $\mathrm{TiO}_{2}$, and nitrogen doped $\mathrm{TiO}_{2}$ with a hybridized $\mathrm{O}_{2 \mathrm{p}}$ and $\mathrm{N}_{2 \mathrm{p}}$ valence band, as well as stable intermediary energy levels within the band gap is shown in Figure S1. Asahi et al. were able to reduce the band gap of $\mathrm{TiO}_{2}$ by increasing the valence band maximum through nitrogen doping via a dual gas operated RF sputtering system ${ }^{7}$, which is represented in Figure $\mathrm{S} 1$ (b). However, Irie et al. were able to show an increase in visible light activity in $\mathrm{N}$-doped $\mathrm{TiO}_{2}$ films by the introduction of intermediary energy levels within the band gap of $\mathrm{TiO}_{2}{ }^{16}$, as shown in Figure S1 (c). Last, Ihara et al. found that doping nitrogen into $\mathrm{TiO}_{2}$ was able to effectively create oxygen vacancies with energy levels just below the conduction band minimum (also shown in Figure S1(c)), which allowed for the absorption of visible light. ${ }^{14}$ These studies suggest that the fabrication techniques used to create $\mathrm{N}$-doped $\mathrm{TiO}_{2}$ films play a critical role in the electronic and optical properties of the doped films.

Another promising method to stably incorporate nitrogen into $\mathrm{TiO}_{2}$ is through the oxidation of TiN, which has also yielded very diverse results. For example, Zhu et al. fabricated $\operatorname{TiN}_{x}$ thin films via $\mathrm{DC}$ sputtering and then annealed the samples at $450^{\circ} \mathrm{C}$, revealing a pure $\mathrm{TiO}_{2}$ anatase phase with no traces of TiN left behind. ${ }^{17}$ However, Brudnik et al. deposited and then oxidized TiN films using the same method, but achieved a pure rutile phase of $\mathrm{TiO}_{2}$ when annealed at $300^{\circ} \mathrm{C}^{18}$ The difference between these two studies was the deposition pressure, which was around $2 \mathrm{~Pa}$ for Zhu et al., and $1 \mathrm{~Pa}$ for Brudnik et al. Clearly, there is a relationship between the sputtering deposition pressure of TiN thin films, and the resulting crystal formation temperature and phase of $\mathrm{TiO}_{2}$ after annealing. In addition to these two cases where a pure phase of $\mathrm{TiO}_{2}$ was formed upon annealing a TiN thin film at different temperatures, Lee et al. ${ }^{19}$ and $\mathrm{Wu}$ et al. ${ }^{20}$ both obtained a mixed phase of anatase and rutile after annealing TiN nanoparticles in air.

One appealing advantage of using the oxidation of $\mathrm{TiN}$ to form $\mathrm{TiO}_{2}$ is the charge separation effect between the two materials. When $\mathrm{TiO}_{2}$ is in contact with metals, photoexcitation allows electrons to transfer from the conduction band of $\mathrm{TiO}_{2}$ to the metals. ${ }^{21 \sim 23}$ The source of this effect is from the difference in the Fermi energy levels between the two materials, which creates a Schottky barrier. This barrier creates a small but substantial electric field which can localize electrons and holes in their respective band energies, and thus increase the lifetime of the photogenerated charge carriers. When the lifetime of photogenerated electron-hole pairs is increased, it can have an advantageous effect on photocatalytic reactions. Although TiN is not a true metal, it exhibits metallic like properties such as high electrical conductivity, and therefore, it can create a Schottky barrier between itself and $\mathrm{TiO}_{2}$. A diagram is presented in Figure $\mathrm{S} 2$ in order to illustrate the charge separation effect between $\mathrm{TiO}_{2}$ and TiN. Here, a UV photon excites an electron from the valence band to the conduction band, and due to the contact area between the $\mathrm{TiO}_{2}$ and $\mathrm{TiN}$ materials, the photogenerated electron is pulled toward the TiN Fermi energy level, which accordingly separates it from its corresponding 
photogenerated hole. Furthermore, when this technique is used, there is the possibility that intermediary layers of $\mathrm{TiON}\left(\mathrm{TiO}_{\mathrm{x}} \mathrm{N}_{\mathrm{y}}\right)$ are formed at the interface between $\mathrm{TiO}_{2}$ and $\mathrm{TiN}$, as the $\mathrm{TiN}$ oxidizes. This layer can primarily help to improve visible light absorption as described above, and also add in the charge separation effect. For example, Figure S2(b) illustrates the energy level diagram of the three layer system involving $\mathrm{TiN}, \mathrm{TiON}$, and $\mathrm{TiO}_{2}$. In this figure, it is shown how electrons are able to be excited via UV light in the $\mathrm{TiO}_{2}$ layer, and via visible light photons in the TiON layer. Since the conduction band level is not changed from $\mathrm{TiO}_{2}$ to $\mathrm{TiON}$ (as the $\mathrm{Ti}_{3 \mathrm{~d}}$ state should not be affected, or only minimally affected), the charge separation effect can still be felt, and photogenerated electrons can transfer from the conduction band of TiON to the Fermi energy level of TiN. Thus, this tertiary system can promote improved visible light absorption from the TiON intermediary layer, and also preserve the charge separation effect.

While there have been several individual studies which have shown the ability to form anatase, rutile, and mixed phase $\mathrm{TiO}_{2}$ by oxidizing TiN, a comprehensive method to controllably produce either phase individually, or both phases simultaneously has not been developed. Furthermore, when TiN oxidizes to $\mathrm{TiO}_{2}$, there is a possibility of creating an intermediary compound of the form $\mathrm{TiO}_{\mathrm{x}} \mathrm{N}_{\mathrm{y}}$, which can be interpreted as a partially oxidized TiN layer, or a partially N-doped $\mathrm{TiO}_{2}$ layer. The ability to generate this intermediary layer is vital to improving the visible light absorption and photoactivity of $\mathrm{TiO}_{2}$, and is a critical challenge in the development of solar-driven photocatalysts.

In this study, we examined the oxidation of TiN films prepared by RF reactive sputtering at different deposition pressures. The TiN deposition parameters were optimized by in-situ plasma diagnostics to insure the proper film stoichiometry and growth rate. Thermal annealing at different temperatures revealed the oxidation kinetics for each film, with the low pressure films oxidizing to the rutile phase of $\mathrm{TiO}_{2}$, the high pressure films oxidizing to anatase $\mathrm{TiO}_{2}$, and the films deposited at moderate pressure showing both anatase and rutile characteristics. In addition, the optical properties of each film revealed a strong absorption in the visible light region, which moved closer to the UV spectrum as the annealing time and temperature increased, indicating that intermediary layers of TiON were able to be formed during the oxidation process. In addition, hetero-junctioned thin films were able to be formed which showed characteristics of both $\mathrm{TiN}$ and $\mathrm{TiO}_{2}$, indicating a unique compositional controllability. Thus, we have shown a simple method for fabricating nitrogen-doped $\mathrm{TiO}_{2}$ with controllable crystallinity and optical absorption, revealing a technique which can readily produce multi-layered visible light responsive coatings which can be used for optoelectronic and photocatalytic applications.

\section{RESULTS AND DISCUSSION}

\subsection{Plasma deposition and characterization}

TiN films were fabricated in a RF sputtering reactor (SPT 120, Plasmionique) using a balanced magnetron cathode. A Ti target (99.9\%, Neyco) was sputtered, using argon as the processing gas and nitrogen as the reactive gas. The deposition pressure was controlled by the Ar flow rate into the deposition chamber, fabricating films at $p=2,3.5,5$, and 14 mtorr with corresponding Ar flow rates of 20,35,50, and $140 \mathrm{sccm}$ respectively, and by keeping the pumping speed constant. The power and frequency were respectively $200 \mathrm{~W}$ and $13.56 \mathrm{MHz}$. TiN films were deposited on three different substrates for different characterization. Samples were prepared on glass slides for optical investigation, on $\mathrm{Si}(100)$ wafers for SEM, XPS, and on ITO coated glass for electrochemical measurements The substrate holder was not biased and not heated. The characteristics of the plasma were monitored in-situ by optical emission spectroscopy (OES, HR2000, Ocean Optics) and by an RF compensated Langmuir probe (Smartprobe, Scientific System) in order to determine the best conditions to deposit TiN films. The emission lines in vacuum for $\operatorname{Ti}(\lambda=499.1 \mathrm{~nm})$ and $\mathrm{N}(\lambda=747.0$ $\mathrm{nm})$, were both normalized against the peak for $\operatorname{Ar}(\lambda=772.6 \mathrm{~nm})$ in order to estimate the relative intensity of titanium and nitrogen excited species in the plasma. Figure 1(a) shows the normalized titanium emission line (Ti/Ar) as a function of the nitrogen flow rate for different pressures. Three distinct regions were labeled within this plot to show the different plasma deposition modes. The first region, region I, indicated the so-called metallic deposition mode. In this particular case the flow of $\mathrm{N}_{2}$ gas was very low, so the target was not poisoned by nitrogen and only metallic Ti was sputtered. 
When the $\mathrm{N}_{2}$ flow rate was increased, there was a competition between the sputtering of Ti by argon, and the local nitride formation of the target by atomic N, which is the so-called target poisoning effect. As a consequence, the normalized titanium emission lines decreased for all of the deposition pressures, as well as the deposition rate, because the formation of a TiN layer on the surface of the target decreased the sputtering rate of Ti. This region, region II, was called the transition mode. As the $\mathrm{N}_{2}$ flow rate was further increased, the normalized Ti emission line became very weak, and this region, region III, was called the compound mode. At these high nitrogen flow rates, the target was fully poisoned by nitrogen, so the deposition rate of TiN on the substrate was very low.

The normalized nitrogen emission line as a function of $\mathrm{N}_{2}$ flow rate for different pressures is shown in Figure 1(b). The N/Ar ratio increased linearly with an increased $\mathrm{N}_{2}$ flow rate and decreased with pressure. This behavior is typical of a discharge regime controlled by the diffusion of charged particles to the reactor walls. Indeed, as shown in Figure 2, the electron temperature $\left(\mathrm{kT}_{\mathrm{e}}\right)$ measured by the Langmuir probe decreased with pressure, and because the latter have less energy, the dissociation rate of nitrogen is decreased which results in the decrease in the emission of atomic nitrogen (see Figure 1(b)). On the contrary, the electron density $\left(n_{e}\right)$ increased with pressure, so the ion current directed to the target became more intense and the sputtering rate of Ti was increased (see Figure 1(a)). Thus, the opposite behavior of normalized atomic $\mathrm{N}$ and atomic Ti emissions in the plasma can both be correlated with the plasma electrical properties (i.e. $\mathrm{kT}_{\mathrm{e}}$ and $\mathrm{n}_{\mathrm{e}}$ ). Moreover, the partial pressure of nitrogen was less at higher pressures (the pressure was adjusted by the argon flow), and could also explain the decrease of the nitrogen emission lines at high pressure (see Figure 1(b)).

Based on plasma diagnostics results, we chose to deposit each film within region II in order to deposit stoichiometric TiN at a reasonable deposition rate. In particular, we chose different $\mathrm{N}_{2}$ flow rates for each deposition pressure which corresponded to similar positions of the normalized $\mathrm{Ti}$ emission lines. There was an optimum operating point along this curve that maximized both the deposition rate and delivered the desired property or properties of the deposited film. Specifically, when there is a low Argon flow rate $(20 \mathrm{sccm}$ to $35 \mathrm{sccm}$ ), the nitrogen flow rate was set between 0.7 to $1 \mathrm{sccm}$, for a medium Argon flow rate (between 35 and $50 \mathrm{sccm}$ ) the nitrogen flow rate was fixed between 1 to $1.5 \mathrm{sccm}$, and at higher Argon flow rate $(140 \mathrm{sccm})$, the nitrogen flow rate was set between 1.5 to $2.5 \mathrm{sccm}$.

XPS depth profiling was performed on a Thetaprobe spectroscope by Thermo Scientific (East Grinstead, UK). The source employed was $\mathrm{Al} \mathrm{K} \alpha$ monocromated radiation running at a power of 140 $\mathrm{W}$, with a spot size of $400 \mu \mathrm{m}$. The Thetaprobe employs a hemispherical analyser and elemental peak narrow scans were recorded at an analyser pass energy of $50 \mathrm{eV}$. Sputter etching was performed using $\mathrm{Ar}^{+}$at $3 \mathrm{kV}$ accelerating voltage, $1 \mu \mathrm{A}$ beam current and $3 \times 3 \mathrm{~mm}^{2}$ raster size. The sputter rate was determined through mechanical profilometry of the etch crater after sputtering and determined to be $0.34 \mathrm{~nm} / \mathrm{min}$. Quantification of the spectra was performed following the removal of a non-linear (Shirley) background and use of the Thermo Avantage software which employs transmission function corrected Wagner sensitivity factors. C 1s hydrocarbon contamination $(285.0 \mathrm{eV})$ was employed as an internal charge reference. SEM was undertaken on a Quanta 200 FEG microscope, of FEI (Cambridge, UK)). The accelerating voltage used was between 15 and $25 \mathrm{kV}$.

\subsection{Film Morphology and Crystal Structure}

The thickness of each of the films was measured by profilometry, and were all within \pm 30 $\mathrm{nm}$. For example, the films deposited at $3 \mathrm{mtorr}$ had an average thickness of $480 \pm 20 \mathrm{~nm}$, the films deposited at 7 mtorr had an average thickness of $492 \pm 15 \mathrm{~nm}$, and the films deposited at $14 \mathrm{mtorr}$ had an average thickness of $508 \pm 15 \mathrm{~nm}$. The higher thicknesses measured for the films deposited at the higher pressure relates to a relative increase in the deposition rate at higher pressures, which is a common finding for RF sputtered thin films. SEM images showing the surface of films deposited at 2 and 14 mtorr are shown in Figure 3. The image reveals a surface which has many triangular sharktooth features which overlap almost continuously over each other. The average size of the features are $\mathrm{h}=36 \pm 11 \mathrm{~nm}$, and $\mathrm{b}=75 \pm 13 \mathrm{~nm}$, where $\mathrm{h}$ is the height of the triangle, and $\mathrm{b}$ is the base of the triangle. At higher pressures, similar shark-tooth features are observed, which are much smaller and less densely packed than for the films deposited at low pressure. These shark-tooth features have an 
average size of $\mathrm{h}=20 \pm 5 \mathrm{~nm}$, and $\mathrm{b}=42 \pm 7 \mathrm{~nm}$. It is well-known that thin films deposited at lower pressures are more dense with a compact bulk structure, whereas those deposited at higher pressure show a more open columnar structure in the bulk with increased levels of porosity ${ }^{24,25}$. This more open columnar structure offers more opportunity for the diffusion of oxygen into the bulk, and significantly affects the oxidation kinetics, which will be discussed later.

All of the as-deposited films displayed a very intense XRD peak centered at $2 \theta=36.8^{\circ}$, which corresponded to the (111) cubic crystal orientation of TiN, shown in Figure 4(a). There was also a small peak observed around $2 \theta=43.2^{\circ}$, which corresponded to the (200) orientation of TiN. The grain size of TiN was estimated from the (111) peak using the Scherrer equation for each of the films before and after annealing at $350^{\circ} \mathrm{C}, 450^{\circ} \mathrm{C}$, and $550^{\circ} \mathrm{C}$. The changes in the estimated grain sizes of the TiN and $\mathrm{TiO}_{2}$ crystals as a function of annealing temperature and time are discussed in the supplementary section (see Supplementary Information). The as-deposited TiN grain size is plotted as a function of the deposition pressure in Figure 5 (a). This figure revealed that as the deposition pressure is increased, the TiN grain size decreased significantly. In general, thin films deposited at low pressure are denser and have a larger grain size, while films deposited at higher pressures typically exhibit higher porosity and smaller grain sizes. This can be explained by the fact that at lower pressures the kinetic energy of the sputtered atoms arriving at the substrate are higher, which will lead to a higher surface mobility of the adatoms, and therefore larger grain sizes.

The film deposited at $p=2$ mtorr showed no significant changes when annealed at $350^{\circ} \mathrm{C}$ up to 24 hours. The only noticeable difference that was present in the XRD scans was a small shift $(\Delta 2 \theta \approx$ $\left.0.1^{\circ} \pm 0.1\right)$ of the (111) peak as the annealing time increased, as well as a slight decrease in the peak height. The shift became very small and after 24 hours the TiN peak at $2 \theta=36.8^{\circ}$ had shifted to $2 \theta=$ $37.0^{\circ}$. This shift in the TiN peak can be attributed to an increase in strain on the crystal lattice that was caused by the annealing process. The strain, however, was not large enough to cause an oxidation of this particular film, due to the high density of the coating resulting from the low deposition pressure. Similarly, after annealing the same film at $450^{\circ} \mathrm{C}$ for up to 24 hours, no noticeable oxidation was observed. Again, a small decrease in intensity and peak shift was observed in the TiN peak centered at $2 \theta=36.8^{\circ}$, with the variance found to be $\Delta 2 \theta \approx 0.1^{\circ} \pm 0.1$. It is clear that for the film deposited at $p=$ 2 mtorr, any temperature up to $450^{\circ} \mathrm{C}$ is not enough to initialize oxidation from $\mathrm{TiN}$ to $\mathrm{TiO}_{2}$ after $24 \sim 48$ hours of annealing.

However, after annealing this film at $550^{\circ} \mathrm{C}$, significant changes were observed in the XRD diffractograms. After 15 and 30 minutes of annealing at $550^{\circ} \mathrm{C}$, a shift in the TiN peak at $2 \theta=36.8^{\circ}$ was observed, similar to the patterns found after annealing for several hours at $350^{\circ} \mathrm{C}$ and $450^{\circ} \mathrm{C}$. When the film was annealed for an hour at $550^{\circ} \mathrm{C}$, the intensity of the TiN peak decreased significantly (less than half its original height), and another peak became observable at $2 \theta=36.15^{\circ}$. This new peak corresponded to the (101) orientation of the $\mathrm{TiO}_{2}$ rutile crystal structure, and after one hour was still less intense than the TiN peak. After annealing this film at $550^{\circ} \mathrm{C}$ for 2 hours, the rutile peak at $2 \theta=$ $36.15^{\circ}$ became much more dominant, and the TiN peak at $2 \theta=36.8^{\circ}$ reduced significantly again. It is apparent that for this very dense film deposited at a very low pressure, it was very hard to oxidize TiN to $\mathrm{TiO}_{2}$. In fact, no oxidation was observed until annealing for an hour at $550^{\circ} \mathrm{C}$, and at no point was the anatase phase for $\mathrm{TiO}_{2}$ seen. The results suggest that the compact nature of this film makes it very difficult to oxidize. The high temperatures required to oxidize the coating have resulted in the formation of rutile rather than anatase as the $\mathrm{TiO}_{2}$ phase.

The TiN film deposited at $p=3.5$ mtorr showed very similar trends to the film deposited at $p$ $=2 \mathrm{mtorr}$ at low temperatures, but diverged from these trends at higher temperatures. For example, when this film was annealed at $350^{\circ} \mathrm{C}$ up to 24 hours, no phases of $\mathrm{TiO}_{2}$ were formed. Similar to the other film deposited at a low pressure, only a small shift in the TiN peak centered at $2 \theta=36.8^{\circ}$ was observed, with a maximum displacement of $\Delta 2 \theta \approx 0.2^{\circ}$. When the same TiN film was annealed at $450^{\circ} \mathrm{C}$, for up to 4 hours, a similar peak shift was observed, again with no distinct $\mathrm{TiO}_{2}$ phases present.

When the TiN film deposited at $p=3.5$ mtorr is annealed at $550^{\circ} \mathrm{C}$, the XRD diffractograms again diverged from the lower temperature results. After annealing for 15 minutes, only a small peak shift was observed for the TiN peak centered at $2 \theta=36.8^{\circ}$. However, after annealing for 30 minutes, in addition to the TiN peak shift, a small peak at $2 \theta=38.6^{\circ}$ was formed which corresponded to the (112) orientation of the anatase phase of $\mathrm{TiO}_{2}$. This is in contrast to the film deposited at $p=2$ mtorr, 
which did not show any anatase peaks for the different annealing temperatures and times. When this film was annealed for an hour, the TiN peak decreased significantly and another peak emerged at $2 \theta=$ $36.15^{\circ}$, corresponding to the $(101)$ orientation of the rutile phase of $\mathrm{TiO}_{2}$. In addition, a very small bump began to appear around $2 \theta=27.5^{\circ}$, corresponding to the (110) orientation of the rutile phase of $\mathrm{TiO}_{2}$. At this annealing temperature and time interval, the anatase peak at $2 \theta=38.6^{\circ}$ remained the same as it was after 30 minutes of annealing, indicating that the anatase crystallites remained unchanged, but relative phase fraction of anatase in the film decreased. After this film was annealed for 2 hours, the rutile (101) peak at $2 \theta=36.15^{\circ}$ became dominant, and the TiN peak disappeared. For this film at these annealing conditions, it appeared that the TiN film is either completely oxidized to $\mathrm{TiO}_{2}$, or is almost fully oxidized with only a very small layer of TiN that is undetectable by XRD. Annealing for 3 hours reveals an identical XRD plot, which indicated that the full oxidation had taken place. It is interesting to note that this film initially oxidized to form anatase, but the rutile became the dominant phase at longer oxidation times. This behaviour is noticeably different from the film deposited at a lower pressure. It is possible that the more porous nature of the film deposited at higher pressure may have enabled oxidation to commence more rapidly, allowing the initial growth of anatase prior to the formation of rutile as the high temperature stable phase.

Unlike the two previous films deposited at low pressures, the TiN thin film deposited at $p=5$ mtorr exhibited significant changes when annealed at $350^{\circ} \mathrm{C}$. The as-deposited plot showed a very strong and broad peak centered at $2 \theta=36.8^{\circ}$, which corresponded to the (111) phase of TiN. After annealing at $350^{\circ} \mathrm{C}$ for 4 hours, the TiN peak decreased around $25 \%$, and slightly broadened towards larger angles. After annealing for 6 hours, the TiN peak again decreased significantly, and was less than half the original peak height. After annealing the film for 8 hours at this temperature, the TiN peak was still present, but again showed a decreased intensity. At this time, a small bump began to appear which was centered at $2 \theta=25.3^{\circ}$, which corresponded to the (101) orientation of the anatase phase of $\mathrm{TiO}_{2}$. In addition to the TiN peak becoming much less intense, the overall shape of this peak became much broader at larger angles, which indicated that there was a second peak contributing to the shape. After annealing for 12 hours, the TiN peak was again greatly reduced, and a clear stronger peak was visible at $2 \theta=38.6^{\circ}$, which corresponded to the (112) peak of anatase. Also, the anatase (101) peak became slightly stronger than before. Overall, at this annealing time and temperature it is clear that anatase was the dominant phase, while the diffractogram still showed an appreciable amount of TiN. It is interesting to note that the (112) orientation of $\mathrm{TiO}_{2}$ shows a stronger peak intensity than the (101) orientation, which is typically the most dominant peak found for anatase. After annealing for 24 hours, the TiN peak was no longer visible, and the (112) anatase peak was the most intense peak observed. The (101) anatase peak became slightly stronger after this time, but the peak was still much less intense than the (112) peak. Annealing for 40 hours revealed an identical profile, indicating that the oxidation from $\mathrm{TiN}$ to $\mathrm{TiO}_{2}$ had been completed, leaving a predominantly (112) oriented phase of anatase. The very slow and gradual change from $\mathrm{TiN}$ to $\mathrm{TiO}_{2}$ at this temperature revealed that this film has a controllable crystallinity, and the ratio of $\mathrm{TiN}$ to $\mathrm{TiO}_{2}$ may be controlled very easily, which can be beneficial for many electronic and opto-electronic applications.

When the TiN film deposited at this pressure was annealed at $450^{\circ} \mathrm{C}$, the change from $\mathrm{TiN}$ to $\mathrm{TiO}_{2}$ was more drastic than at $350^{\circ} \mathrm{C}$. After one hour of annealing at $450^{\circ} \mathrm{C}$, the XRD pattern showed no peak at $2 \theta=36.8^{\circ}$, suggesting that no TiN was present. In addition, a large peak at $2 \theta=38.6^{\circ}$ was observed, corresponding to the (112) peak of anatase and a very small and broad peak also formed at $2 \theta=37.9^{\circ}$, corresponding to the (004) peak of anatase. A small (101) peak of anatase phase was also observable. When the annealing time was increased up to 48 hours, the peak height at $2 \theta=38.6^{\circ}$ increased steadily, but the overall shape of the XRD pattern remained the same. This clearly showed that at $450^{\circ} \mathrm{C}$, the TiN film deposited at $p=5$ mtorr oxidized to $\mathrm{TiO}_{2}$ very fast (within an hour), and was stable up to 2 days of further annealing. Again, at this temperature the (112) preferred orientation of anatase was observed.

After annealing at $550^{\circ} \mathrm{C}$, the TiN film showed a very similar trend to the film annealed at $450^{\circ} \mathrm{C}$, suggesting that no new oxidation processes were occurring. When the film was annealed for 4 hours, the TiN peak completely disappeared and the (112), (004), and (101) peaks of anatase appeared. The oxidized film again exhibited a (112) preferred orientation. The only noticeable difference between annealing at $550^{\circ} \mathrm{C}$ compared to $450^{\circ} \mathrm{C}$ is that the (004) peak of anatase is much less broad, 
and more pronounced. This indicated a higher degree of crystallinity in the film, which was expected when annealing at a higher temperature. As the annealing time increased to 48 hours, the only changes seen in the XRD diffractograms were a gradual increase in the (112) peak height, the overall spectral shape remained the same.

When TiN films were deposited at $p=14$ mtorr, a very drastic change in the crystallinity during annealing was observed, which differs from all of the previous films dramatically. At $350^{\circ} \mathrm{C}$, the film quickly changed crystallinity, similar to the film prepared at $p=5$ mtorr. However, now a (101) preferential orientation of anatase emerged, as seen by a very intense and narrow peak at $2 \theta=$ $25.3^{\circ}$, shown in Figure 4(b). (Note, that the peak around $2 \theta=28^{\circ}$ originates from the underlying silicon substrate). Annealing at $450^{\circ} \mathrm{C}$ and $550^{\circ} \mathrm{C}$ revealed a similar change in crystallinity, with the resulting films demonstrating a strong (101) preferential orientation. This change occurs much faster at these higher temperatures, but gives almost identical XRD spectra. The changes in the crystal size as a function of deposition pressure, annealing time, and temperature for the films deposited at 14 mtorr are shown in Figure 5 (b). It is clear that for all temperatures, that as expected, increasing the annealing time increased, leads to larger grain sizes. In addition, the growth in the grain size happens much quicker at higher temperatures $\left(550^{\circ} \mathrm{C}\right)$ compared to lower temperatures $\left(350^{\circ} \mathrm{C}\right)$. The maximum crystal size estimated was approximately $70 \mathrm{~nm}$ for each of the annealing temperatures.

The control of the compositional properties of the different TiN films after annealing is highly dependent on the deposition pressure, and annealing temperature/time. For example, the films deposited at 2 and 3.5 mtorr show no observable oxidation in XRD when annealed at $350^{\circ} \mathrm{C}$ and $450^{\circ} \mathrm{C}$. We therefore assume that the stoichiometry of these films effectively remains at 1:0 ratio of $\mathrm{TiN}: \mathrm{TiO}_{2}$ at these conditions. However, when these films were annealed at $550^{\circ} \mathrm{C}$, different phases of $\mathrm{TiO}_{2}$ became visible, and the peak heights varied with time. However, for the films deposited at 14 mtorr, when annealed at $350^{\circ} \mathrm{C}$, a steady decrease in the TiN XRD peak was observed, and a gradual increase in the anatase peak was also observed. With a film deposited at this pressure and annealed at this temperature, it may be possible to control the $\mathrm{TiN}: \mathrm{TiO}_{2}$ ratio. However, when this film was annealed at $450^{\circ} \mathrm{C}$ and $550^{\circ} \mathrm{C}$, the TiN peak immediately disappeared, due to oxidation occurring very rapidly when the film is more porous. Thus at these temperatures, it seems to be very difficult to control the $\mathrm{TiN}: \mathrm{TiO}_{2}$ ratio. Although there were many difficulties in controlling the ratio for every deposition pressure and each annealing temperature, 4 regions were found which could offer some relative phase ratio control for the films: (1) deposited at 2 mtorr and annealed at $550^{\circ} \mathrm{C}$, (2) deposited at 3.5 mtorr and annealed at $550^{\circ} \mathrm{C},(3)$ deposited at 5 mtorr and annealed at $350^{\circ} \mathrm{C}$, and (4) deposited at 14 mtorr and annealed at $350^{\circ} \mathrm{C}$. For these 4 regions, the $\mathrm{TiN}: \mathrm{TiO}_{2}$ content was calculated from the XRD peak heights as a function of time, and are shown for the films deposited at 2 mtorr and 3.5 mtorr in Figure 6(a), and for the films deposited at 5 mtorr and 14 mtorr in Figure 6(b). These plots can thus be a guide to depositing films with a desired $\mathrm{TiN}: \mathrm{TiO}_{2}$ ratio, although the compositional estimate is only an approximation from the XRD data. For example, a TiN:TiO ${ }_{2}$ ratio of 1:3 was required, this can possibly be achieved by depositing a film at 5 mtorr and annealing at $350^{\circ} \mathrm{C}$ for between 6 and 8 hours, or from a film deposited at $3.5 \mathrm{mtorr}$ and annealed at $550^{\circ} \mathrm{C}$ for approximately 30 minutes. The main difference between these two conditions, however, is that different crystal phases of $\mathrm{TiO}_{2}$ will be grown (rutile at 3.5, and anatase at 5 mtorr), showing a further parameter for the desired controllable deposition of $\mathrm{TiN} / \mathrm{TiO}_{2}$ films.

It is clear that the deposition pressure played a significant role in the ability of the TiN films to oxidize to $\mathrm{TiO}_{2}$, as well as the crystal phase and orientation of the $\mathrm{TiO}_{2}$ grown. Table 1 shows the dominant crystal structure for each film deposited at different pressures for each of the corresponding annealing temperature. From this table, it is very clear to see that just by changing the TiN deposition pressure, different phases and orientation of crystalline $\mathrm{TiO}_{2}$ can be formed after annealing. As the oxidation process for each of the films fabricated at each deposition pressure vary with time, it is therefore possible to create $\mathrm{TiN}$ films, which can oxidize to $\mathrm{TiO}_{2}$ with different crystal phases, orientations, and concentrations depending on the desired application necessary.

XPS depth profiling was utilized to determine how the oxidation front progresses for the films as a function of annealing time. The depth profiling results for the 5 mtorr deposited films oxidized at $350^{\circ} \mathrm{C}$ for different annealing times are given in Figure $\mathbf{S 3}$ and the bulk film compositions given in Table II. An overlay of the N 1s peak at varying points in the profile for the $350^{\circ} \mathrm{C}$ exposures after 4 and 12 hours is shown in Figure 7. From Table II, it can be seen that the as-deposited TiN reference 
sample exhibited a $\mathrm{TiN}_{\mathrm{x}}$ stoichiometry of $\mathrm{TiN}_{0.87}$. Upon oxidation, the trend for increasing $\mathrm{O}$ concentration (and decreasing $\mathrm{N}$ concentration) in the bulk as a function of annealing time is clear. Interestingly, from Figure S3, it can be seen that independent of annealing time, below the highly oxidized surface region (10-20 nm), the bulk composition of the thin films is invariant as a function of depth. In Figure 7, the $\mathrm{N}$ 1s component showed the presence of peaks representative of $\mathrm{TiO}_{\mathrm{x}} \mathrm{N}_{\mathrm{y}}$ at the surface, but for all the profiles, below a depth of $10 \mathrm{~nm}$, the $\mathrm{N} 1 \mathrm{~s}$ peak shape is invariant, exhibiting a strong peak at $397.1 \mathrm{eV}$, with a binding energy and peak shape corresponding to $\mathrm{TiN}^{26,27}$ Hence, for these particular annealed films the $\mathrm{TiO}_{\mathrm{x}} \mathrm{N}_{\mathrm{y}}$ layer has a thickness of $<10 \mathrm{~nm}$. Below this layer a multiphase $\mathrm{TiN} / \mathrm{TiO}_{2}$ structure is formed.

With regard to the high $\mathrm{O}$ concentration at the surface and increasing $\mathrm{O}$ concentration in the bulk as a function of annealing time, the results can be explained by there being a typical solid state oxidation process occurring in the surface region, but rapid diffusion paths for $\mathrm{O}$ also exist within the microstructure of the coating and this then promotes general oxidation in the coating bulk. This is supported by the SEM cross-section micrographs given in Figure 8 for films deposited at 5 mtorr and oxidized at $350^{\circ} \mathrm{C}$ for 6 hours and 48 hours. The semi-columnar structure of the TiN thin film is clearly visible in the micrograph after 6 hours (no $\mathrm{TiO}_{2}$ peaks observed in XRD), whereas after 48 hours the columnar structure is no longer visible, due to bulk oxidation (only $\mathrm{TiO}_{2}$ peaks visible in $\mathrm{XRD}$ ) and the resulting microstructure is rather featureless

Two schematic diagrams are presented in order to explain the oxidation behaviour for films deposited at low pressure and high pressures (Figure 8). The diagams focus on the diffusion of oxygen into the films to oxidise a layer of TiN to firstly form a thin interfacial $\mathrm{TiO}_{\mathrm{x}} \mathrm{N}_{\mathrm{y}}$ layer and then bulk $\mathrm{TiO}_{2}$. There are different diffusion paths along which oxygen can migrate and react with $\mathrm{TiN}$ in vapour deposited TiN thin films. The diffusion paths are: (i) along the surface; (ii) along voids at column boundaries; (iii) along grain boundaries; (iv) through the bulk lattice. The ease of oxygen migration along these diffusion paths decreases progressively from (i) to (iv), due to the progressive increase in atomic density at these regions in going from (i) to (iv). Hence, for the more dense films deposited at low pressure, it is to be expected there will be less oxidation in the bulk than for those with a more open columnar structure, deposited at higher pressures. This is in agreement with the XRD results which showed that for the dense films deposited at low pressures oxidation only occurred at high temperatures $\left(550^{\circ} \mathrm{C}\right)$, forming rutile at 2 mtorr and rutile plus anatase at 3.5 mtorr. For the more porous films deposited at higher pressures, there is still an initial surface oxidation, but as the annealing time continues, the more open columnar structure gives rise to rapid diffusion paths for oxygen to diffuse into the bulk film as seen from the XPS profiles and SEM cross-section images. Thus, the column boundaries act as sites for the formation of $\mathrm{TiO}_{2}$ upon further annealing. The result is a thin oxidized layer on the top of these films, and anatase crystals forming within the bulk of the film. Bulk film oxidation then creates significantly more contact area between the $\mathrm{TiO}_{2}$ and $\mathrm{TiN}$ regions (with a $\mathrm{TiO}_{\mathrm{x}} \mathrm{N}_{\mathrm{y}}$ interfacial layer), which should increase the charge separation effect.

With regard to the principal formation of rutile for low pressure deposited films and anatase for high pressure deposited films upon annealing, this may be understood as follows. Rutile is known to be the stable phase at room temperature and pressure and at high temperatures and pressures, with anatase being the metastable phase. However, at temperatures below $400-600^{\circ} \mathrm{C}$, anatase is often the first phase formed, as it is kinetically stabilized, either due to its simpler structural arrangement or lower surface energy. ${ }^{28}$ For the TiN thin films examined here, rutile is formed on the dense films deposited at low pressures and hence the oxide is predominantly formed at the surface. For these films, no oxide was observed by XRD until the annealing temperature reached $550^{\circ} \mathrm{C}$, hence the higher temperature may promote formation of rutile as the first crystalline phase observed. However, for the less dense TiN films, the oxide is growing predominantly within the bulk of the TiN film and anatase is observed at lower annealing temperatures $\left(350^{\circ} \mathrm{C}\right)$. When annealed at higher temperatures $\left(550^{\circ} \mathrm{C}\right)$, anatase is either retained or a mixed anatase/rutile structure develops. Within the bulk TiN film, there is clearly physical resistance to the formation of the $\mathrm{TiO}_{2}$ phase from the surrounding $\mathrm{TiN}$ grains and pressure will be exerted on the emerging anatase crystallites. Muscat et al have noted that the $\mathrm{TiO}_{6}$ octahedra can be more easily compressed in the anatase structure compared to the packing arrangement of these octahedra in rutile. ${ }^{29}$ Hence, the ability of the anatase structure to be more easily compressed may be stabilizing retention of the anatase phase compared to rutile under these growth conditions. 


\subsection{Optical Properties}

The optical properties of the oxidized TiN films showed a large variance in their spectra, and the changes were directly aligned with the XRD results. For instance, the films deposited at $p=2$ mtorr and 3.5 mtorr showed no change in their transmission spectra after annealing at both $350^{\circ} \mathrm{C}$ and $450^{\circ} \mathrm{C}$ (Table I). However, very small changes were present for both films when annealed at $550^{\circ} \mathrm{C}$ with a maximum transmission achieved of only $0.06 \%$ and $3.5 \%$, respectively (not shown). This small transmission indicated that the oxidation layer on these films was either non-existent or very small, and the films were still mainly composed of TiN.

When the film deposited at $p=5 \mathrm{mtorr}$ film was annealed at $350^{\circ} \mathrm{C}$, the transmission spectra began to increase steadily at higher wavelengths, shown in Figure 9(a). As the annealing continued, the transmission also increased at higher wavelengths but remained very low below $500 \mathrm{~nm}$, and only achieved a maximum transmission of $\sim 50 \%$ after 48 hours of annealing. After annealing for 72 hours, the transmission was much higher above $400 \mathrm{~nm}$, and a sharp decrease in transmission due to absorption was seen at $380 \mathrm{~nm}$, corresponding to a band gap energy of $3.2 \mathrm{eV}$, characteristic of anatase $\mathrm{TiO}_{2}$. When this film was annealed at $450^{\circ} \mathrm{C}$, the changes in transmission occurred much faster, and the sharp anatase band edge emerged after only 4 hours of annealing. After being annealed at $550^{\circ} \mathrm{C}$, this change happened even faster, with the strong absorption edge becoming present only after 1 hour of annealing (not shown).

The film deposited at 14 mtorr allowed some transmission before any annealing, seen between $450 \mathrm{~nm}$ and $800 \mathrm{~nm}$, with a maximum transmission of $\sim 8 \%$. Annealing at $350^{\circ} \mathrm{C}$ for 2 hours showed a large increase in transmission at longer wavelengths, and a gradual decrease down to $450 \mathrm{~nm}$, shown in Figure 9(b). As the annealing continued, the absorption edge of the spectra began to shift to lower wavelengths, eventually forming a sharp edge indicative of anatase $\mathrm{TiO}_{2}$ after 48 hours of annealing. Annealing at higher temperatures shows a more drastic change, with the sharp band edge appearing after less than 2 hours of annealing at $450^{\circ} \mathrm{C}$, and within 30 minutes when annealing at $550^{\circ} \mathrm{C}$ (not shown).

The optical properties of the films accurately reflect the change from pure TiN to predominantly $\mathrm{TiO}_{2}$, with indications that a mixed $\mathrm{TiN} / \mathrm{TiO}_{2}$ structure (lowering the transmission) or $\mathrm{N}$-doped $\mathrm{TiO}_{2}$ structure (decreasing the band gap) is occurring between these two extremes. As the oxidation time increased, regardless of temperature, an increase in the estimated band gap was observed with a maximum band gap achieved of approximately $3.2 \mathrm{eV}$, corresponding to the anatase phase of $\mathrm{TiO}_{2}$. Therefore, when the band gap appears to be lower than this energy, it can be due to either the rutile phase of $\mathrm{TiO}_{2}$ (which has a band gap of $3.0 \mathrm{eV}(413 \mathrm{~nm})$ ), or an N-doped $\mathrm{TiO}_{2}$ structure. In the samples prepared at low deposition pressure, the rutile phase of $\mathrm{TiO}_{2}$ was observed, and therefore this may be a partial reason for the decreased band gap energy, however, at higher pressure there is no indication that the rutile phase is present. Therefore, the reduction of the band gap energy at higher pressures must come from the insertion of nitrogen in the $\mathrm{TiO}_{2}$ lattice. Looking back at Figure S1 (b) and (c), the reduction of the apparent band gap in some of these films can be attributed to either a hybridization of the valence band energies of oxygen and nitrogen, or the introduction of stable band energies within the $\mathrm{TiO}_{2}$ band gap. When a very small band gap was observed, it may be due to a large concentration of interstitial doping, because this energy level is deep within the band gap of $\mathrm{TiO}_{2}(0.7 \mathrm{eV}$ above the valence band), and thus a significantly smaller band gap energy would be observed. Furthermore, when the apparent band gap is only slightly smaller than that of anatase $\mathrm{TiO}_{2}$, it is more likely that it is due to a hybridization of the $\mathrm{O}_{2 \mathrm{p}}$ and $\mathrm{N}_{2 \mathrm{p}}$ states. In either case, it can be assumed that the visible light absorption is directly due to the incorporation of nitrogen within the $\mathrm{TiO}_{2}$ lattice, as both phases of pure $\mathrm{TiO}_{2}$ absorb visible light very poorly.

For all of the films deposited at high and low pressures, it has been shown that different annealing conditions can result in the co-existence of both $\mathrm{TiO}_{2}$ and $\mathrm{TiN}$ in these films, resulting in a heterogeneous, dual phase thin film. While $\mathrm{TiO}_{2}$ is a semi-conductor, TiN has shown electric properties similar to metals, and therefore this hetero-junction between $\mathrm{TiO}_{2}$ and $\mathrm{TiN}$ may be able to act as a charge separation junction. This ability to tailor the phase and composition between $\mathrm{TiO}_{2}$ and TiN is potentially very useful, and can have far reaching applications in many fields such as optoelectronics, superconductivity, and photocatalysis. 


\subsection{Photoelectrochemical Performance}

Linear sweep voltammograms under white light irradiation of the oxidized TiN films were measured after annealing at $350^{\circ} \mathrm{C}$ and $450^{\circ} \mathrm{C}$ for different time intervals. The excitation lamp produced an average power of $1 \mathrm{~mW} / \mathrm{cm}^{2}$, and the area of irradiation for each sample was kept constant at $1 \mathrm{~cm}^{2}$. For simplicity, the photocurrent density as a function of the sweeping bias voltage of the sample deposited at 3.5 mtorr is shown in Figure 10, but the trends for all the deposition pressures were identical with respect to annealing temperature and time, and only differed in the maximum photocurrent density, to be discussed later. Sweeps were conducted from $-0.8 \mathrm{~V}$ up to 1.3 V. At low biasing, negligible photocurrent was measured, however, when the biasing voltage increased above $1.2 \mathrm{~V}$ a sharp increase in photocurrent was observed, corresponding to a water splitting reaction $(\sim 1.23 \mathrm{eV})$. Therefore, for visual clarity we show the photocurrent generation only between $-0.8 \mathrm{~V}$ and $1.0 \mathrm{~V}$. For the samples annealed at $350^{\circ} \mathrm{C}$, when the biasing voltage was steadily increased from $-0.8 \mathrm{~V}$, a gradual increase in the photocurrent density was observed up until $0.0 \mathrm{~V}$. When the bias was increased above $0.0 \mathrm{~V}$, the photocurrent density increased more rapidly until $0.5 \mathrm{~V}$, where a plateau in photocurrent density was achieved. For all of the TiN films deposited at every pressure and annealed at $350^{\circ} \mathrm{C}$, the photocurrent increased with increasing annealing time with a maximum photocurrent density observed for the maximum annealing time of 24 hours. However, for all of the films annealed at $450^{\circ} \mathrm{C}$, a maximum photocurrent density was observed after annealing for 1.5 hours, and then the current density began to decrease.

The open circuit voltages measured for our samples are in accordance with the reported data for such $\mathrm{pH}$ values. ${ }^{30}$ For our samples, we measured open circuit voltages between $-0.5 \mathrm{~V}$ and $-0.7 \mathrm{~V}$, which depended on the deposition pressure and annealing time/temperature. In general, the asdeposited films had slightly lower open circuit voltages, and as the annealing time increased, so did the open circuit voltage. It is well known that nitrogen doped titania is an n-type semiconductor having a Fermi level energy higher than the redox potential of the electrolyte. This means, there is an upward bending of the valence and conductive band's edges when the semiconductor is in contact with the electrolyte, and the $\mathrm{N}$ doped $\mathrm{TiO}_{2}$ surface will has a positive charge due to the electronic loss in the depletion region or the charge space. ${ }^{31}$

Upon light irradiation, the OCV shifted to more negative values by $300 \pm 100 \mathrm{mV}$ and $100 \pm$ $20 \mathrm{mV}$ under UV light and visible light, respectively. This variation in the OCV is called "photovoltage" and it is consistent with other reported values. ${ }^{32}$ This shift is due to the change in the flat band potential upon photon absorption. ${ }^{31} \mathrm{Pu}$ et al. have reported a photovoltage of $510 \mathrm{mV}$ and $616 \mathrm{mV}$ upon white light irradiation in the case of porous and compact films, respectively. ${ }^{33}$ In fact, when the appropriate photons are absorbed, the band bending will increase due to the extra-electronic exchange on the interface $\mathrm{TiO}_{2}$ /solution and this will lead to the shift of the new flat band to more negative values.

This white light and visible light induced band bending is responsible for the enhancement in water splitting kinetics. It is well known that the valance band of $\mathrm{TiO}_{2}$ (having photo excited holes) is more positive than the $\mathrm{O}_{2} / \mathrm{H}_{2} \mathrm{O}$ redox potential, and the conductive band (containing the photo excited electrons) is lower than $\mathrm{H}_{2} / \mathrm{H}_{2} \mathrm{O}$ redox potential. The conductive band bottom determines the reduction potential of the photo excited electrons while the top of the valence band determines the oxidizing ability of the photo generated holes. On the other hand, under light irradiation, the electronic exchange at the $\mathrm{TiO}_{2}$ /solution reflects the themodynamic ability of a redox reaction to take place at the interface, and the exchanged electrons (from the semiconductor to the solution) reduces $\mathrm{H}^{-}$to $\mathrm{H}_{2}$ while the valance band holes oxidize $\mathrm{O}^{-2}$ into $\mathrm{O}_{2}$. The measured photocurrent at the anodic biasing quantifies the oxidation power of the photogenerated holes reaching to the $\mathrm{TiO}_{2} /$ electrolyte interface, and the value of photocurrent is directly related to the kinetic $\mathrm{O}_{2}$ generation.

Intermittent photocurrent density measurements were obtained for each of these films with a constant biasing voltage of $0.5 \mathrm{~V}$, and plotted as a function of time. For simplicity, the photocurrent density was plotted for the TiN samples deposited at 14 mtorr, and annealed at $350^{\circ} \mathrm{C}$ and $450^{\circ} \mathrm{C}$, and shown in Figures 11 (a) and (b), respectively. In both figures, it is clear to see that when the white light source was turned on, appreciable photocurrent was generated, and when the lamp was turned off the photocurrent decreased immediately to negligible values. This is important to note, because the sharp decrease in the photocurrent is directly attributed to the removal of white light irradiation. Similar to Figure 7, it is possible to observe the change in maximum photocurrent generated at 
different annealing conditions. In particular, once again it is seen that after annealing at $350^{\circ} \mathrm{C}$, the oxidized TiN films create more photocurrent as the annealing time increases, with a maximum observed photocurrent of $160 \pm 10 \mu \mathrm{A} / \mathrm{cm}^{2}$. However, when the samples are annealed at $450^{\circ} \mathrm{C}$, a distinct increase in photocurrent was observed, with a maximum current density of $280 \pm 7 \mu \mathrm{A} / \mathrm{cm}^{2}$ achieved after 1.5 hours of annealing.

In order to determine the effect of just the visible light on the photocurrent generation of the samples, a UV filter was placed in front of the samples during irradiation. Under no illumination, negligible current was measured, with an average value of $1 \pm 1 \mu \mathrm{A} / \mathrm{cm}^{2}$ found. Therefore, the photocurrent generated under irradiation is only due to the incident light, and not from the intrinsic dark properties of the films. The maximum visible light photocurrent generated in the samples was plotted as a function of annealing time for all of the oxidized TiN samples and are shown in Figure 12 (a) and (b) for annealing conditions at $350^{\circ} \mathrm{C}$ and $450^{\circ} \mathrm{C}$, respectively. There are several trends which are present in both of the figures. First, for all of the films deposited at $350^{\circ} \mathrm{C}$, it is clear that as the deposition pressure increases, so does the photocurrent density, with a maximum photocurrent of 9.5 $\mu \mathrm{A} / \mathrm{cm}^{2}$ found for the sample deposited at 14 mtorr and annealed for 24 hours. The increase in photocurrent as a function of deposition pressure and annealing time is directly related to the oxidation kinetics of each film. For example, annealing the low pressure films ( 2 and 3.5 mtorr) at $350^{\circ} \mathrm{C}$ showed no significant structural changes in the XRD plots, and no formation of the anatase phase. However, the films deposited at higher pressures (5 and 14 mtorr), showed drastic changes in their respective optical and crystalline properties when annealing at $350^{\circ} \mathrm{C}$, and they accordingly showed significantly enhanced photocurrent generation. In particular, the films deposited at 5 mtorr and 14 mtorr showed optical band gaps within the visible light range when annealing at $350^{\circ} \mathrm{C}$, and thus they have the ability to absorb visible light. Therefore, the increase in photocurrent for these samples is directly related to their ability to generate photo-electrons from the visible light, while the low pressure samples are not.

The trend for the samples annealed at $450^{\circ} \mathrm{C}$ was similar to the samples annealed at $350^{\circ} \mathrm{C}$, but showed more photocurrent generation. For example, the highest visible light photocurrent density was measured to be $21 \mu \mathrm{A} / \mathrm{cm}^{2}$ for the sample deposited at 14 mtorr, and annealed for 1.5 hours. We attribute the peak in photocurrent generation after only 1.5 hours of annealing to the change in optical properties of the films. The band gap energy of the films at this annealing temperature show the ability to absorb visible light, while annealing for longer times at this temperature steadily decrease the band gap energy. Therefore, less visible light photons are absorbed when the samples are annealed longer than 1.5 hours at $450^{\circ} \mathrm{C}$, and we see a peak in activity at 1.5 hours.

In addition to the pure white light and visible light photocurrent measurements, a very interesting and unexpected effect was observed. In Figure 13 (a) and (b), the white light source was turned on and off 6 times, and then after the last light-on cycle, we places a UV filter in front of the light source so that only visible light photons could reach the photoanodes. For the films deposited at 2 and 3.5 mtorr, the photocurrent dropped immediately, similar to when the light source was turned off. This was because these samples did not oxidize readily, and could not absorb visible light. However, for the samples prepared at 5 and 14 mtorr, when then UV filter was inserted, the photocurrent density did not decrease immediately, and actually dissipated very slowly. An example of this is shown in Figure S3, for the sample deposited at $5 \mathrm{mtorr}$ and annealed at $350^{\circ} \mathrm{C}$. It is clear to see in this figure that as the annealing time increases, it takes much longer for the photocurrent to come to a steady-state equilibrium. In fact, after annealing at this temperature for 24 hours, it takes more than one minute for the photocurrent to relax to an equilibrium density. We believe this effect is the result of efficient charge separation in these samples, because the deposition and annealing conditions indicate that a multi-phase $\mathrm{TiN} / \mathrm{TiO}_{2}$ film is present. The difference in the Fermi energy levels of these two materials is strong enough to create a Schottky barrier, and thus an electric field at the junction between them. Thus, electron-hole pairs are able to be effectively separated as the junction grows in size and strength, directly related to the increased annealing time. This 'memory effect' is very unique, and can have many applications for optoelectronic devices, and is currently being investigated further.

\section{CONCLUSIONS}

This study has shown a simple and versatile method to produce $\mathrm{TiO}_{2}$ with various crystal orientations and phases via the oxidation of TiN films, and their resulting photoactivity under visible 
light irradiation. The primary step in this process was the deposition of TiN thin films, which was observed and controlled by optical emission spectroscopy as well as Langmuir probe measurements. Using these tools, optimal films of TiN were fabricated at high and low pressures, which showed very large differences in their as-deposited crystal grain size. After the resulting films were annealed at different temperatures and for different time intervals, significant changes were observed in the crystalline and optical properties of each film, which were specific to each deposition pressure. There was a relationship between the deposition pressure and the resulting crystal phase and orientation of $\mathrm{TiO}_{2}$. It was found that films deposited at lower pressures favored the formation of rutile more easily, while anatase was promoted by depositing $\mathrm{TiN}$ at higher pressures and $\mathrm{TiO}_{2}$ growth in the TiN film bulk. A thin $\mathrm{TiO}_{\mathrm{x}} \mathrm{N}_{\mathrm{y}}$ interfacial layer develops between the $\mathrm{TiN}$ and $\mathrm{TiO}_{2}$ upon oxidation. Furthermore, it was possible to manipulate the deposition and annealing conditions in order to obtain films with both $\mathrm{TiO}_{2}$ and $\mathrm{TiN}$ present, indicating the possibility of hetero-junctioned thin films with controllable optical, crystalline, and compositional properties. Relatively high amounts of photocurrent were generated by white and visible light irradiation, showing indications of effective water splitting. In addition, an unexpected memory effect was observed, showing a significantly enhanced charge relaxation time for the photo-generated charge carriers. These films can therefore be very promising for applications in photocatalysis, photovoltaic devices, and other optoelectronic devices which require visible light excitation and enhanced charge carrier lifetimes.

Acknowledgements: The authors are grateful for funding provided by the European Commission FP7 project NATIOMEM (245513-2). The authors would also like to thank Dr. Luca Lozzi for his contribution to the SEM work. 
References:

[1] A. Fujishima, K. Honda, Nature 238, 37 (1972).

[2] A. O'Malley, B.K. Hodnett, Studies in Surface Science and Catalysis 110, 1137 1144 (1997).

[3] K. Shankar, G.K. Mor, H.E. Prakasam, S. Yoriya, M. Paulose, O.K. Varghese, C.A. Grimes, Nanotechnology, 18, 065707 (2007)

[4] W. Smith, W. Ingram, and Y.-P. Zhao, Chem. Phys. Lett. 479, 270-273 (2009).

[5] W. Choi, A. Termin, M.R. Hoffman, Journal of Physical Chemistry, 98, 13669 (1994).

[6] R. Dholam, N. Patel, A. Santini, A. Miotello, International Journal of Hydrogen Energy, 35, 9581 (2010).

[7] R. Asahi, T. Morikawa, T. Ohwaki, K. Aoki, Y. Taga, Science, 293, 269 (2001).

[8] C.Y. Kwong, W.C.H. Choy, A.B. Djurisic, P.C. Chui, K.W. Cheng, W.K. Chan, Nanotechnology, 15, 1156 1161 (2004)

[9] S. Higashimoto, N. Kitahata, K. Mori, M. Azuma, Catalysis Letters 10149 (2004)

[10] W. Smith, Y.-P. Zhao, Journal of Physical Chemistry C, 112, 19635 (2008).

[11] S. Sato, Chemical Physics Letters, 123, 126 128 (1986)

[12] X. Jiang, Y. Wang, C. Pan, Journal of the American Ceramic Society, 94, 4078 4083 (2011)

[13] Y.-M. Lin, Y.-H. Tseng, J.-H. Huang, C.-C. Chao, C.-C. Chen, I. Wang, Environmental Science and Technology, 40, 1616 1621 (2006)

[14] T. Ihara, M. Miyoshi, Y. Iriyama, O. Matsumoto, S. Sugihara, Applied Catalysis B Environmental, 42, 403 409 (2003)

[15] J. L. Gole, J.D. Stout, C. Burda, Y. Lou, X. Chen, Journal of Physical Chemistry B, 108, $1230 \sim 1240$ (2003)

[16] H. Irie, Y. Watanabe, K. Hashimoto, Journal of Physical Chemistry B, 5483 5486 (2003)

[17] L. Zhu, J. Xie, X. Cui, J. Shen, X. Yang, Z. Zhang, Vacuum, 84, 797 802 (2010).

[18] A. Brudnik, M. Bucko, M. Radecka, A. Trenczek-Zajac, K. Zakrzewska, Vacuum, 82 936-941 (2008).

[19] D.-B. Lee, G.-Y. Kim, J.-K. Lee, Metals and Materials International, 9, 43 46 (2003).

[20] Z. Wu, F. Dong, W. Zhao, S. Guo, Journal of Hazardous Materials, 157, 57 63 (2008)

[21] V. Subramaniam, E.E. Wolf, P.V. Kamat, Journal of the American Chemical Society, 126, $4943(2004)$

[22] T. Hirakawa, P.V. Kamat, Journal of the American Chemical Society, 127, 3928 (2005)

[23] W. Smith, S. Mao, G. Lu, A. Catlett, J.H. Chen, Y.P. Zhao, Chemical Physics Letters, 485, $171(2010)$

[24] J.A. Thornton, Journal of Vacuum Science and Technology, 11, 666 (1974)

[25] Z.G. Li, S. Mayake, Applied Surface Science 255, 9149 (2009)

[26] M.A. Baker, T.P. Mollart, P.N. Gibson, W. Gissler, Journal of Vacuum Science and

Technology A 15, 284 (1997)

[27] M.A. Baker, S.J. Greaves, E. Wendler, V. Fox, Thin Solid Films 377-378, 473 (2000)

[28] D.A.H.Hanaor, C.C.Sorrell Journal of Materials Science 46, 855 (2011)

[29] J. Muscat, V. Swarmy, N.M. Harrison, Physical Review B, 65, 224112 (2002)

[30] F Spadavecchia, G Cappelletti, S Ardizzone, M Ceotto, L Falciola, Journal of Physical Chemistry C, 115 (2011) 6381-6391.

[31] A. Bott, Current Separations, 3 (1998) 87-91.

[32] A. Fujishima, X. Zhang, D.A. Tryk, Surface Science Reports, 63 (2008) 515-582.

[33] P. Pu, H. Cachet, E. M. Sutter, Electrochimica Acta 55 (2010) 5938-5946. 

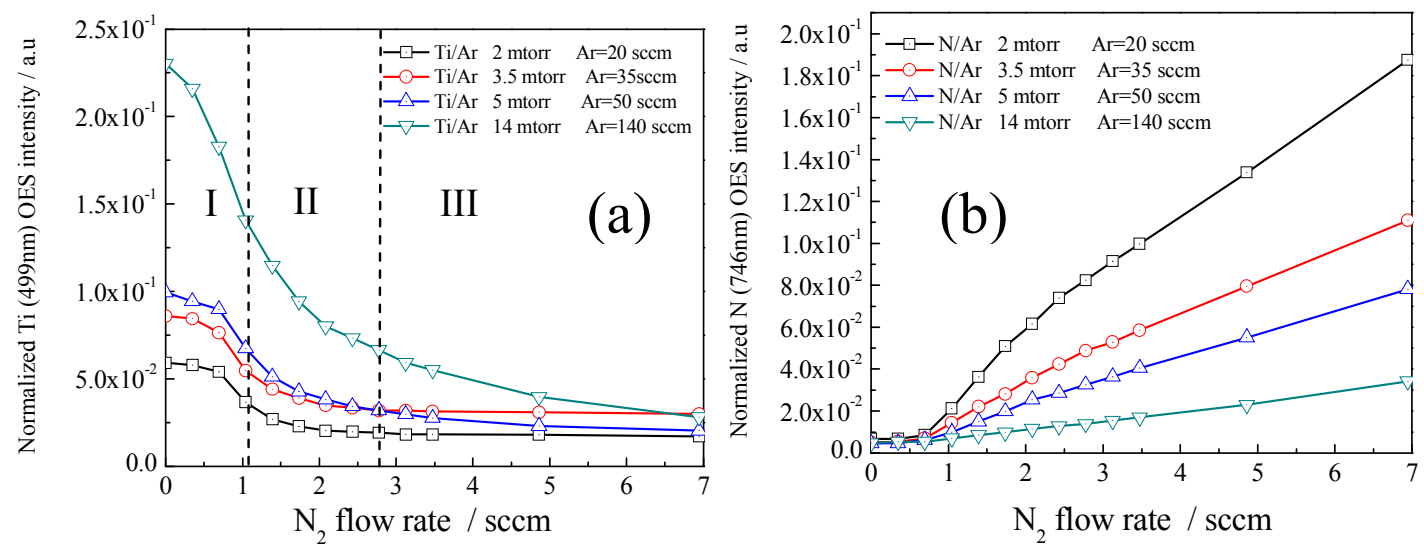

Figure 1: (a) Normalized titanium peak observed by OES as a function of $\mathrm{N}_{2}$ flow rate at 4 different deposition pressures and argon flow rates, and (b) normalized nitrogen peak observed by OES as a function of $\mathrm{N}_{2}$ flow rate at 4 different deposition pressures and argon flow rates. 




Figure 2: Electron temperature and electron density measured by Langmuir probe as function of pressure for a $\mathrm{N}_{2}$ flow rate of $2 \mathrm{sccm}$. 


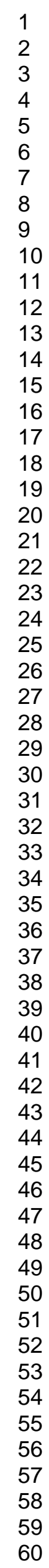
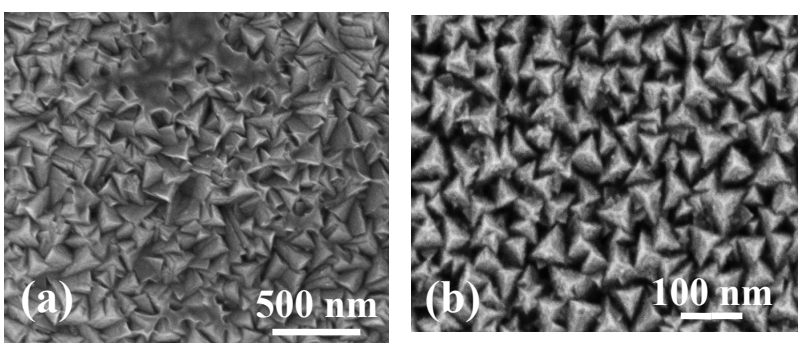

Figure 3: SEM surface images of the films deposited at (a) 2 mtorr; (b) 14 mtorr 

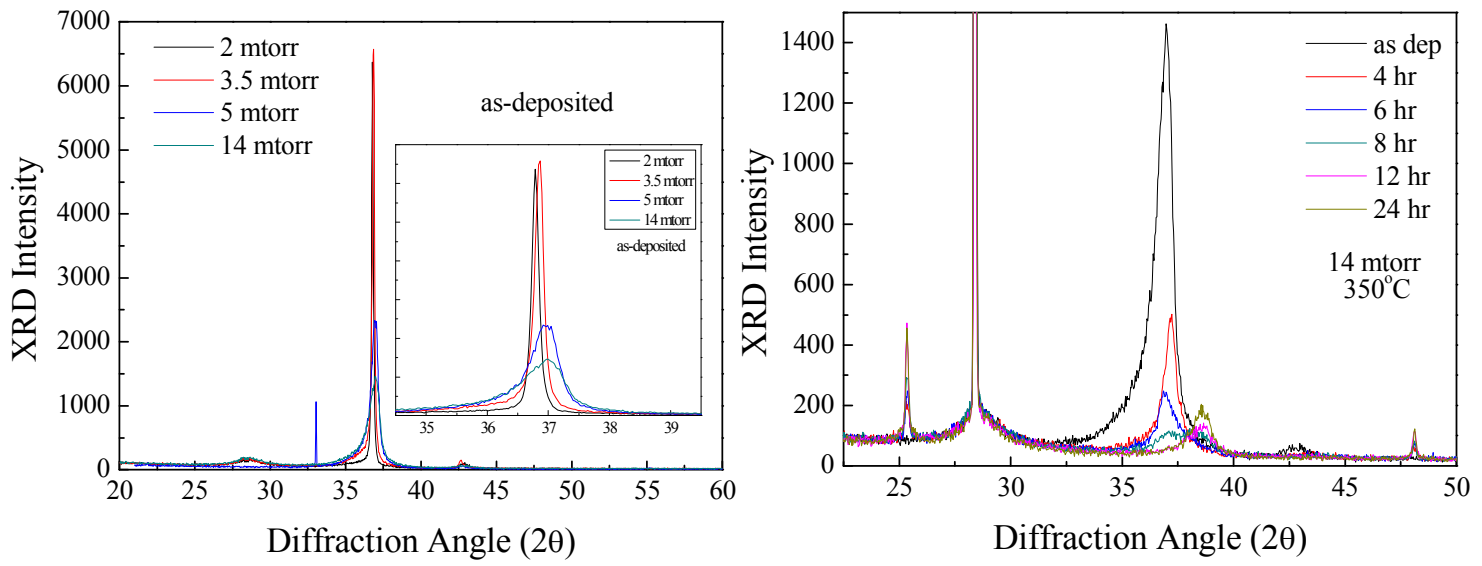

Figure 4: XRD patterns for (a) the as-deposited TiN thin film fabricated at 2, 3.5, 5, and 14 mtorr, and (b) XRD patterns for the TiN film deposited at $p=14$ mtorr, and annealed at $350^{\circ} \mathrm{C}$ up to 24 hours. 

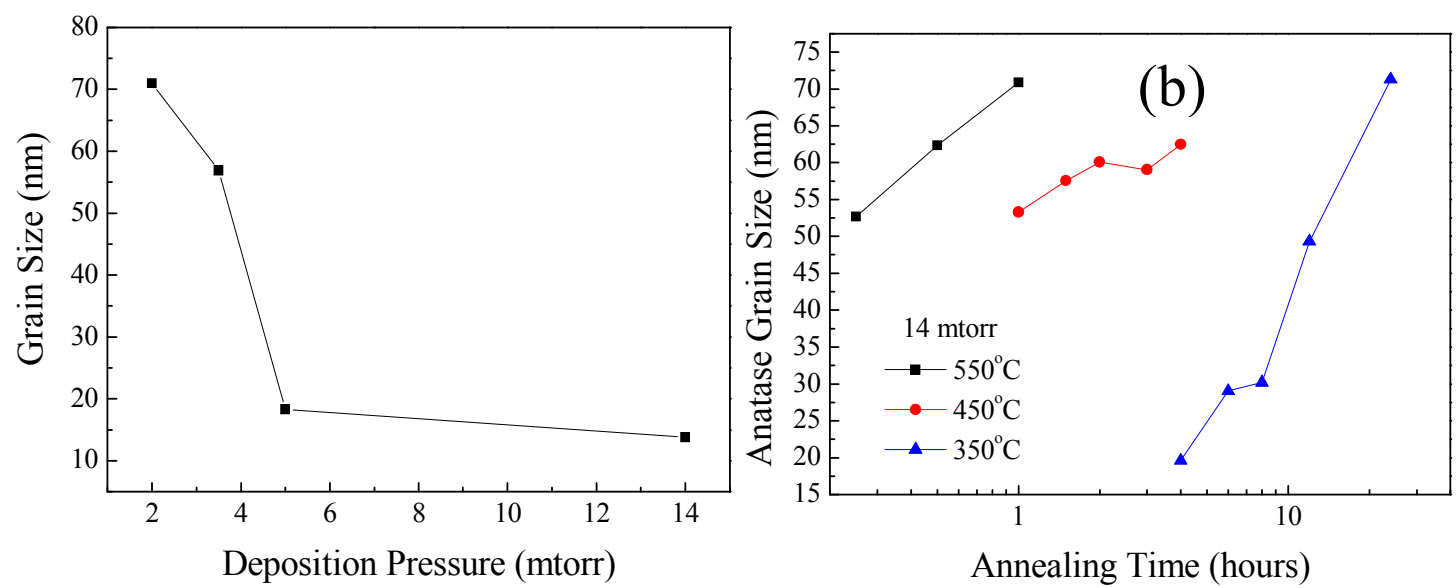

Figure 5: (a) The as-deposited TiN grain size as a function of the deposition pressure. (b) The estimated grain size of the anatase phase of $\mathrm{TiO}_{2}$ as a function of annealing time when annealed at $350^{\circ} \mathrm{C}, 450^{\circ} \mathrm{C}$, and $550^{\circ} \mathrm{C}$. 



Figure 6: The calculated relative percentage of $\mathrm{TiN}$ and $\mathrm{TiO}_{2}$ as a function of time when annealing (a) films prepared at 2 mtorr and 3.5 mtorr and annealed at $550^{\circ} \mathrm{C}$, and (b) films prepared at $5 \mathrm{mtorr}$ and $14 \mathrm{mtorr}$ and annealed at $350^{\circ} \mathrm{C}$. 

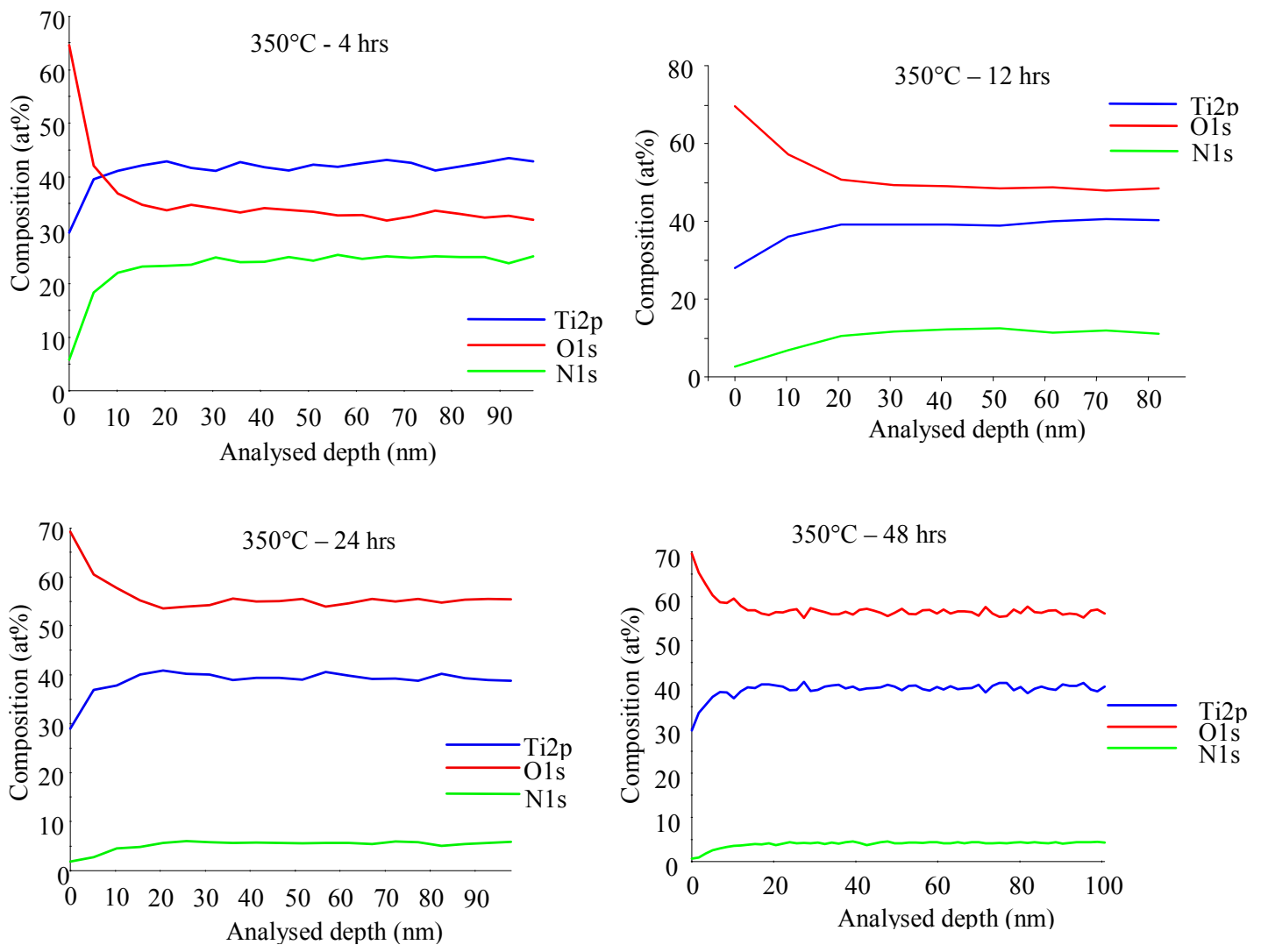

Figure 7: XPS depth profiles for TiN thin films deposited at $5 \mathrm{mtorr}$ and annealed for times of $4,12,24$ and 48 hours. 

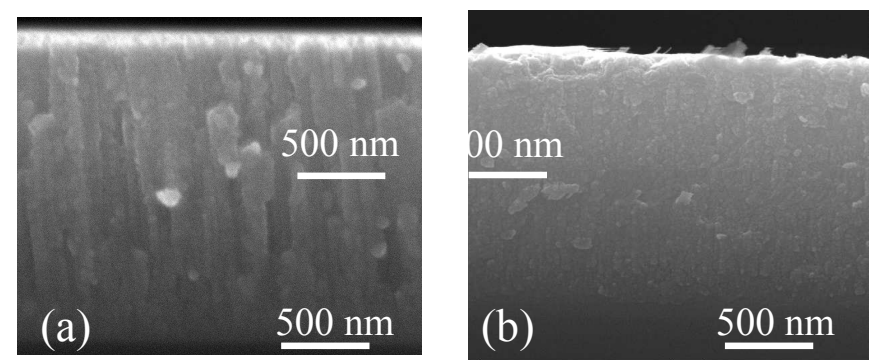

Figure 8: SEM cross-sectional images for thin films deposited at 5 mtorr and annealed at $350^{\circ} \mathrm{C}$ for (a) 6 hours; (b) 48 hours 

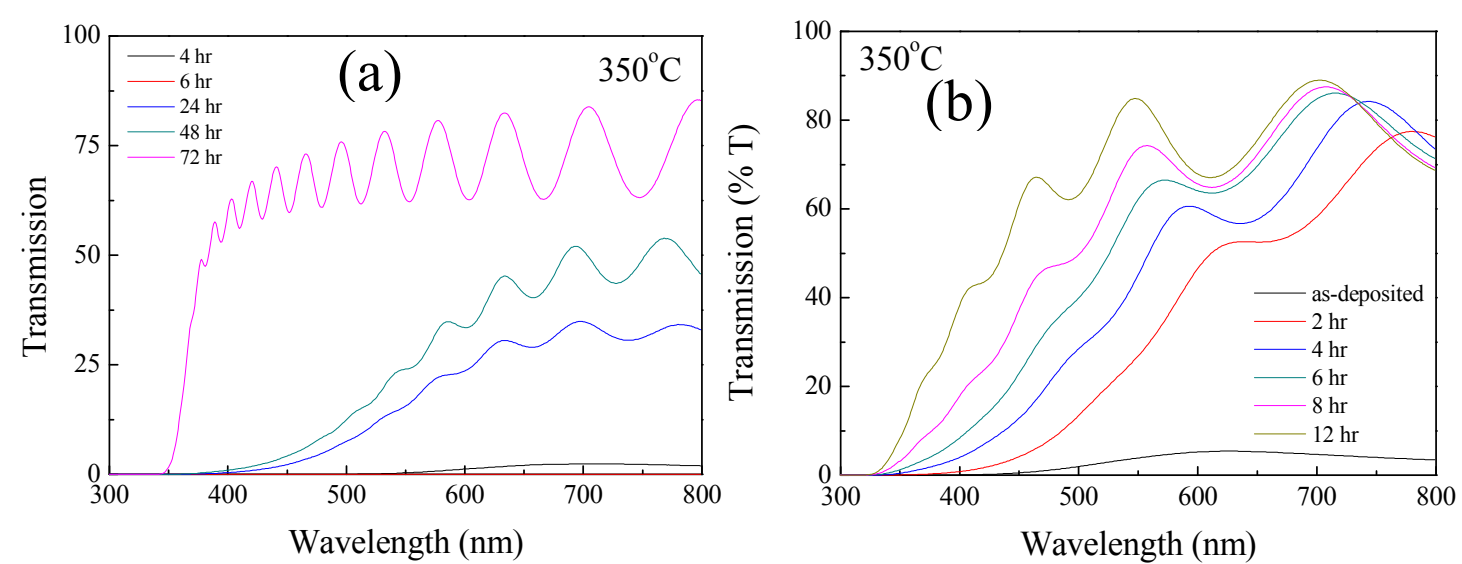

Figure 9: Transmission spectra for the TiN thin films deposited at (a) $p=5 \mathrm{mtorr}$, and (b) $p=14$ mtorr annealed at $350^{\circ} \mathrm{C}$. 


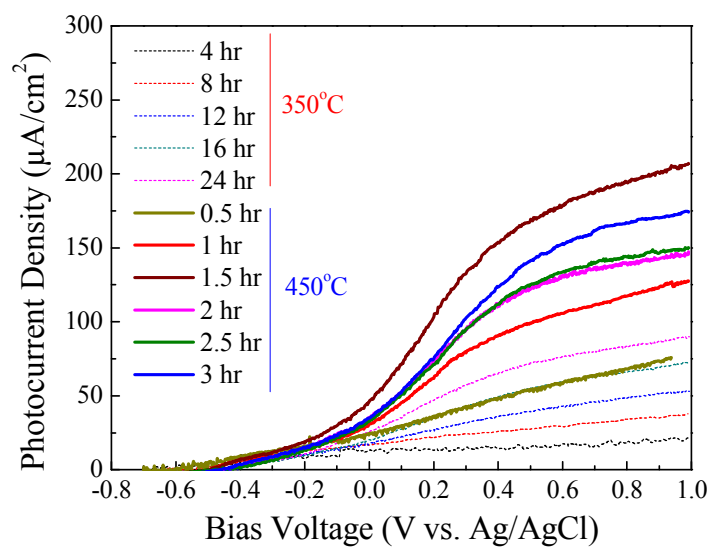

Figure 10: Linear sweep voltammagrams under white light irradiation of TiN films deposited at 3.5 mtorr and annealed at $350^{\circ} \mathrm{C}$ and $450^{\circ} \mathrm{C}$. 

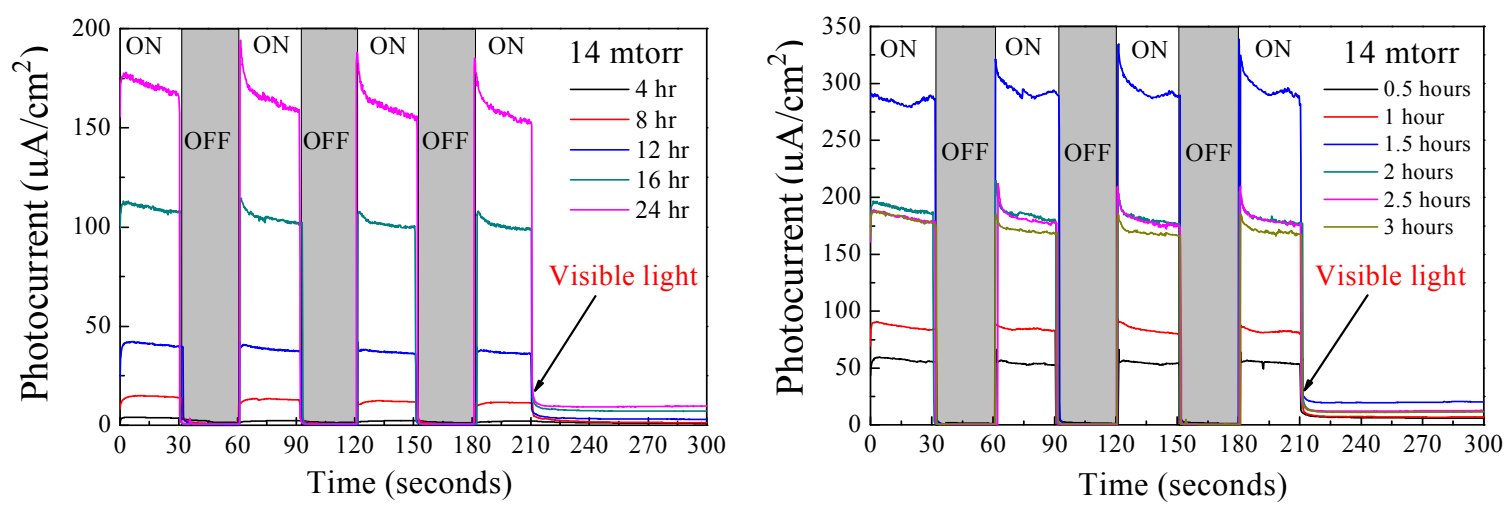

Figure 11: Intermittent photocurrent measurements of the TiN films deposited at 14 mtorr and annealed at (a) $350^{\circ} \mathrm{C}$, and (b) $450^{\circ} \mathrm{C}$. 

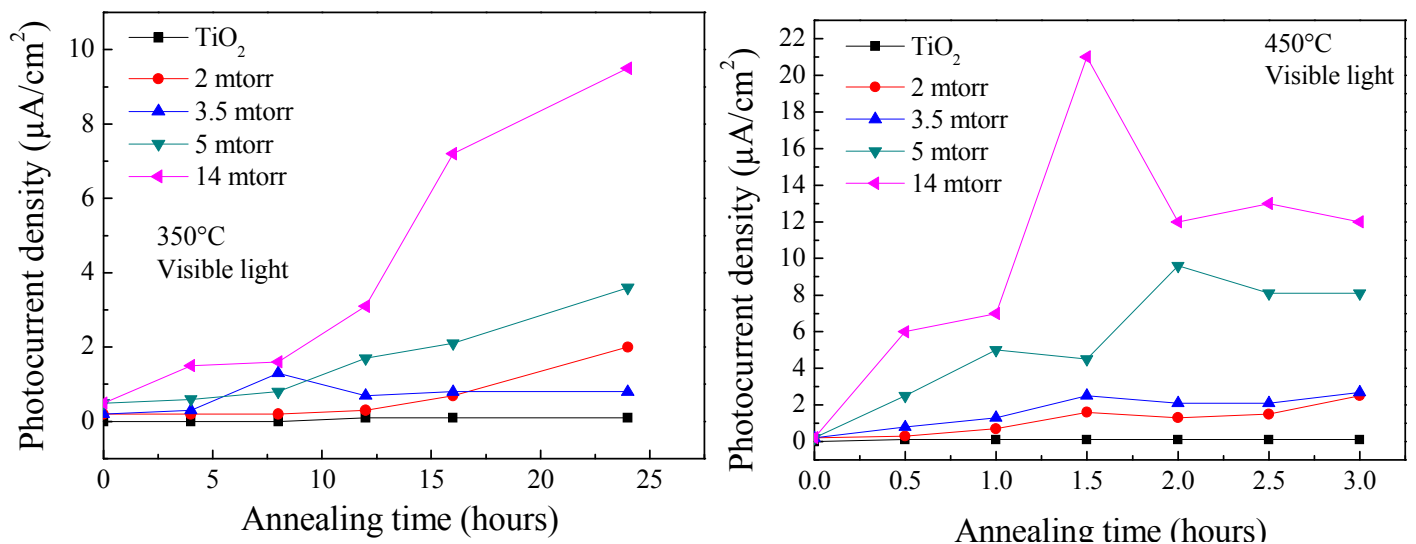

Figure 12: Maximum photocurrent generated in samples and annealed at (a) $350^{\circ} \mathrm{C}$, and (b) $450^{\circ} \mathrm{C}$. 
1

2

3

4

5

6

7

8

9

10

11

12

13

14

15

16

17

18

19

20

21

22

23

24

25

26

27

28

29

30

31

32

33

34

35

36

37

38

39

40

41

42

43

44

45

46

47

48

49

50

51

52

53

54

55

56

57

58

59

60

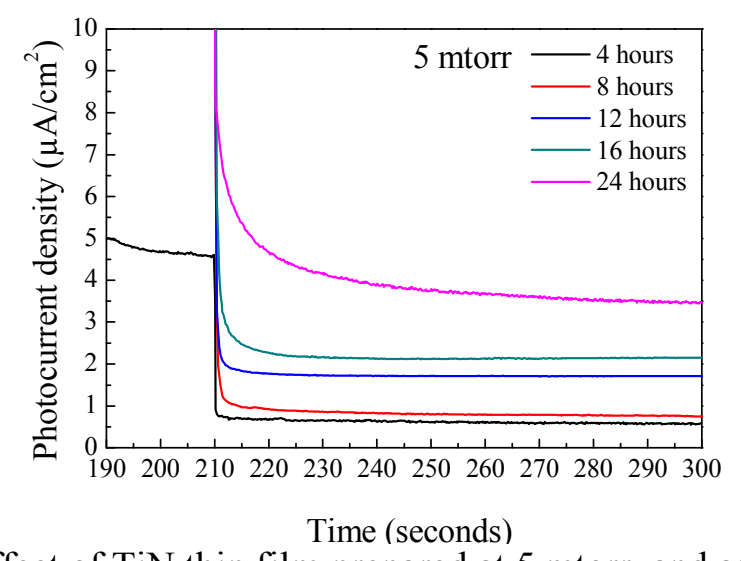

Figure 13: Memory-effect of TiN thin film prepared at 5 mtorr, and annealed at $350^{\circ} \mathrm{C}$ for several time intervals. 
Table I. The change in crystal structure for TiN films deposited at different pressures after annealing at $350^{\circ} \mathrm{C}, 450^{\circ} \mathrm{C}$, and $550^{\circ} \mathrm{C}$. The numbers in the parenthesis represent the dominant crystal orientation, as determined by XRD.

\begin{tabular}{cccc}
\hline \hline & \multicolumn{3}{c}{ Annealing Temperature } \\
\cline { 2 - 4 } Deposition Pressure & $\mathbf{3 5 0}^{\circ} \mathbf{C}$ & $\mathbf{4 5 0}^{\circ} \mathbf{C}$ & $\mathbf{5 5 0}^{\circ} \mathbf{C}$ \\
\hline 2 mtorr & No change (TiN) & No change (TiN) & $\mathrm{TiO}_{2}$ Rutile (101) \\
3.5 mtorr & No change (TiN) & No change (TiN) & $\mathrm{TiO}_{2}$ Rutile $(101)+$ \\
& & & Anatase (112) \\
5 mtorr & $\mathrm{TiO}_{2}$ Anatase (112) & $\mathrm{TiO}_{2}$ Anatase (112) & $\mathrm{TiO}_{2}$ Anatase (112) \\
14 mtorr & $\mathrm{TiO}_{2}$ Anatase (101) & $\mathrm{TiO}_{2}$ Anatase (101) & $\mathrm{TiO}_{2}$ Anatase (101) \\
\hline \hline
\end{tabular}

Table II. Bulk composition of the TiN thin films deposited at 5 mtorr and annealed at $350^{\circ} \mathrm{C}$ for varying times, determined from XPS depth profiles.

\begin{tabular}{|c|c|c|c|c|}
\hline Samples & $\begin{array}{c}\text { Ti (at.\%) } \\
\text { bulk }\end{array}$ & $\begin{array}{c}\mathbf{N}(\mathbf{a t .} \%) \\
\text { bulk }\end{array}$ & $\begin{array}{c}\mathbf{O} \text { (at.\%) } \\
\text { bulk }\end{array}$ & $\begin{array}{c}\text { TiO } \\
\text { stoichiometry }\end{array}$ \\
\hline TiN (as-deposited) & 39 & 34 & 27 & $\mathrm{TiO}_{0.69} \mathrm{~N}_{0.87}$ \\
\hline $4 \mathrm{hrs}$ & 43 & 25 & 32 & $\mathrm{TiO}_{0.74} \mathrm{~N}_{0.58}$ \\
\hline $12 \mathrm{hrs}$ & 40 & 11 & 49 & $\mathrm{TiO}_{1.23} \mathrm{~N}_{0.28}$ \\
\hline $24 \mathrm{hrs}$ & 39 & 6 & 55 & $\mathrm{TiO}_{1.41} \mathrm{~N}_{0.15}$ \\
\hline $48 \mathrm{hrs}$ & 40 & 4 & 56 & $\mathrm{TiO}_{1.40} \mathrm{~N}_{0.10}$ \\
\hline
\end{tabular}




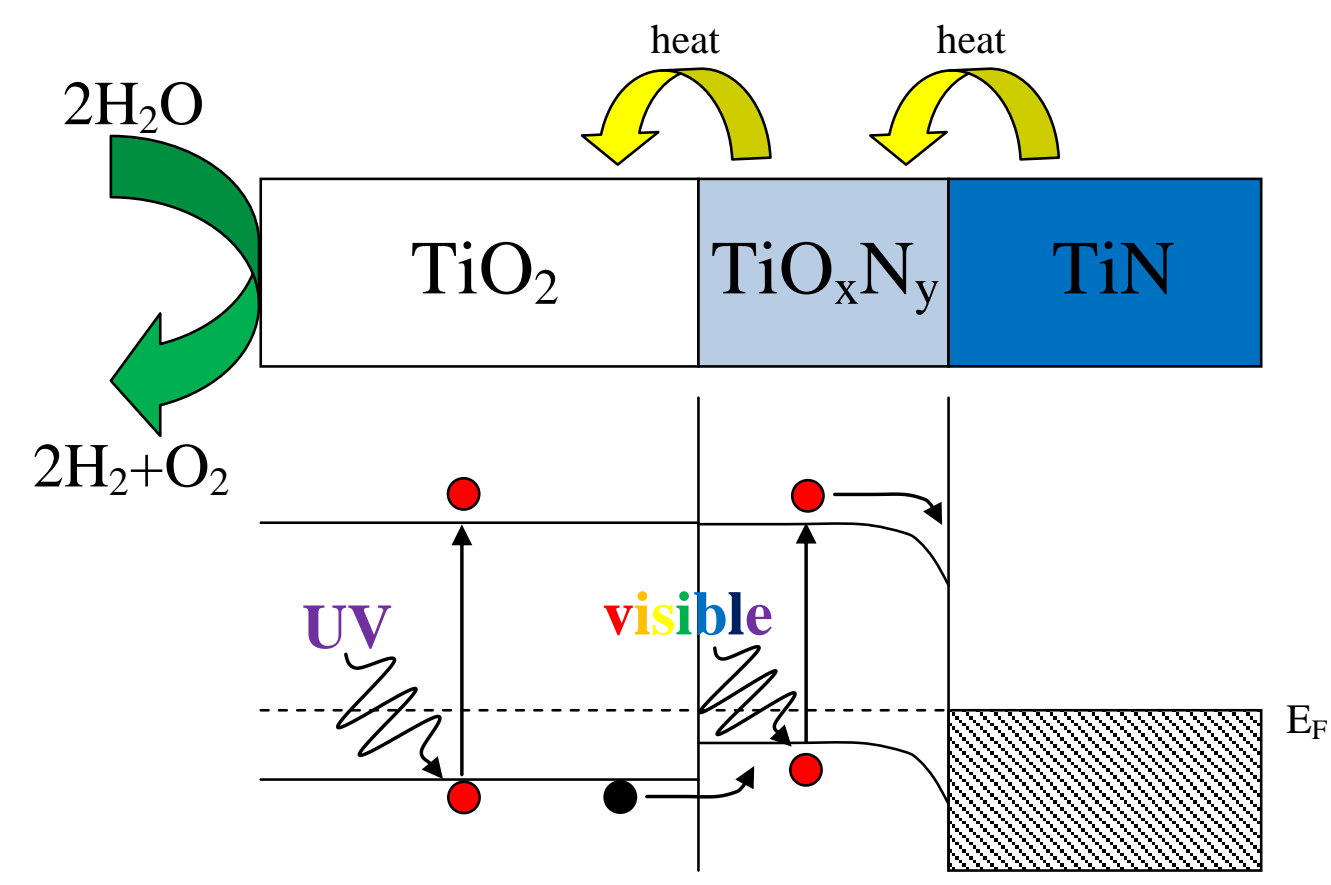


Scheme 1: Low pressure deposition

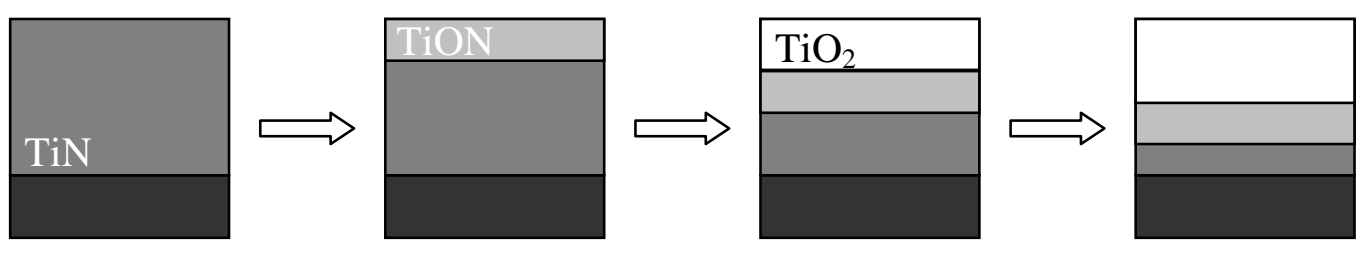

Scheme 2: High pressure deposition
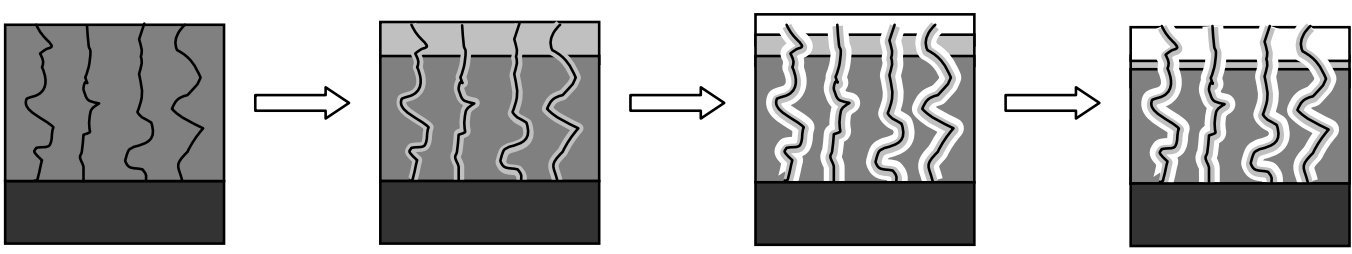